\title{
TESTS ON SENT SPECIMENS TO STUDY GEOMETRY EFFECTS IN THE BRITTLE TO DUCTILE TRANSITION
}

\author{
Patrick Le Delliou ${ }^{1}$, Joumana El-Gharib ${ }^{2}$ \\ ${ }^{1}$ Expert Engineer, EDF R\&D Division, Moret-sur-Loing, France (patrick.le-delliou@edf.fr) \\ ${ }^{2}$ Research Engineer, EDF R\&D Division, Clamart, France
}

\begin{abstract}
The accurate prediction of ductile fracture behaviour plays an important role in structural integrity assessments of critical engineering structures under fully plastic regime, including nuclear reactors and piping systems. Many structural steels and aluminium alloys generally exhibit significant increases in fracture toughness, characterized by the J-integral, over the first few $\mathrm{mm}$ of stable crack extension $(\Delta \mathrm{a})$, often accompanied by large increases in background plastic deformation. Conventional testing programs to measure crack growth resistance $(\mathrm{J}-\Delta \mathrm{a})$ curves employ three-point bend, $\mathrm{SEN}(\mathrm{B})$, or compact, CT. However, laboratory testing of fracture specimens to measure resistance curves $(\mathrm{J}-\Delta \mathrm{a})$ consistently reveals a marked effect of absolute specimen size, geometry, relative crack size (a/W ratio) and loading mode (tension vs. bending) on R-curves. These effects observed in R-curves have enormous practical implications in defect assessments and repair decisions of in-service structures under low constraint conditions, such as pressurized piping systems with surface flaws.

This paper presents the on-going work to develop specimens and test procedures to study geometry effects (e.g., triaxiality effects) in the brittle to ductile transition of carbon-manganese steels, the basic idea being to compare the results obtained on these specimens with the results obtained on CT specimens. A clamped SENT specimen was chosen for this study. In a previous work, finite element computations were done to optimize the specimen shape and to develop the $\eta$-factor, the shape factor $F$ (to compute K) and the normalized compliance $\mu$. Preliminary tests conducted at room temperature, have shown that some adjustments of the test procedure should be made.

New tests have been conducted on modified specimens (shallower notch), first at $20^{\circ} \mathrm{C}$ to check that the procedure is well established in the ductile regime, and then around $-60^{\circ} \mathrm{C}$ in the brittle to ductile region. The results are compared with those obtained on CT12.5 specimens.
\end{abstract}

\section{INTRODUCTION}

The accurate prediction of ductile fracture behaviour plays an important role in structural integrity assessments of critical engineering structures under fully plastic regime, including nuclear reactors and piping systems. Many structural steels and aluminium alloys generally exhibit significant increases in fracture toughness, characterized by the J-integral, over the first few $\mathrm{mm}$ of stable crack extension $(\Delta \mathrm{a})$, often accompanied by large increases in background plastic deformation. Conventional testing programs to measure crack growth resistance ( $\mathrm{J}-\Delta \mathrm{a})$ curves employ three-point bend, $\mathrm{SEN}(\mathrm{B})$, or compact, CT. However, laboratory testing of fracture specimens to measure resistance curves $(\mathrm{J}-\Delta \mathrm{a})$ consistently reveals a marked effect of absolute specimen size, geometry, relative crack size (a/W ratio) and loading mode (tension versus bending) on R-curves. For the same material, deep-notch bend, SE(B), and CT specimens yield low R-curves while shallow-notch SE(B), single-edge notch tension, SENT, and middle-crack tension, $\mathrm{M}(\mathrm{T})$, specimens yield larger toughness values at similar amounts of crack growth (Figure 1). These effects observed in R-curves have enormous practical implications in defect assessments and repair decisions of in-service structures under low constraint conditions, such as pressurized piping systems with surface flaws (Nyhus, 2003). These crack configurations generally 
develop low levels of crack-tip stress triaxiality (associated with the predominant tensile loading which develops in pressurized piping systems), thereby contrasting sharply to conditions present in deeply cracked $\mathrm{SE}(\mathrm{B})$ and $\mathrm{CT}$ specimens.

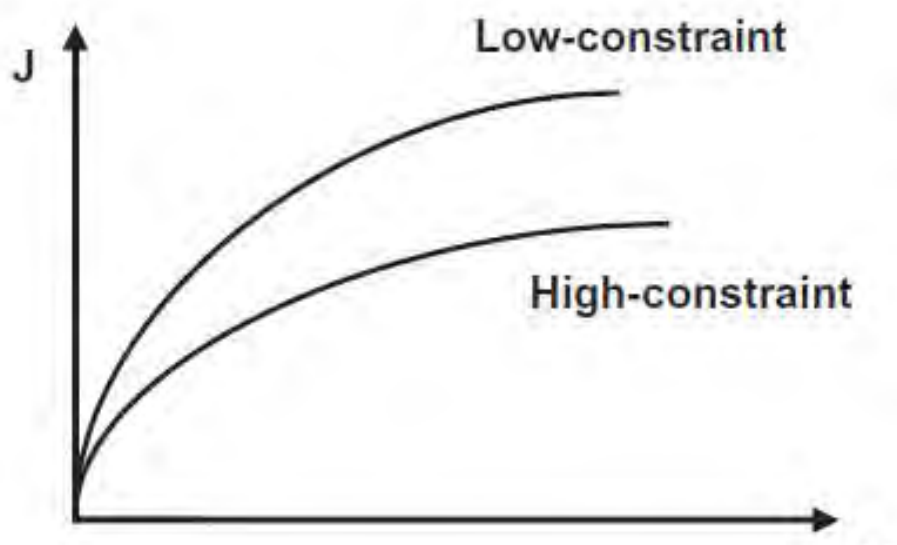

$\Delta \mathrm{a}$

Figure 1. Constraint effect on J-R curves.

This paper presents the on-going work to develop specimens and test procedures to study geometry effects (e.g., triaxiality effects) in the brittle to ductile transition of carbon-manganese steels, the basic idea being to compare the results obtained on these specimens with the results obtained on CT specimens. In a previous work (Le Delliou, 2012), finite element computations were done to optimize the specimen shape and to develop the $\eta$-factor, the shape factor $F$ (to compute $K$ ) and the normalized compliance $\mu$. Preliminary tests conducted at room temperature, have shown that some adjustments of the test procedure should be made.

New specimens have been machined with shallower notches $(\mathrm{a} / \mathrm{W}=0.4)$, to get $\mathrm{a}_{0} / \mathrm{W}=0.5$ after fatigue pre cracking. Fatigue pre cracking was conducted in 4-point bending to avoid damaging the backside of the notch. Moreover, the specimens were cut in the TS (Transverse-Short) direction of the plate to get lower toughness properties, and less plasticity during the tests. New tests have been conducted, first at $20^{\circ} \mathrm{C}$ to check that the procedure is well established in the ductile regime, and then around $-60^{\circ} \mathrm{C}$ in the brittle to ductile region. The results are compared with those obtained on CT12.5 specimens.

\section{SPECIMEN DESIGN}

The specimen design is fully described in (Le Delliou, 2012) and will not be recalled here. At this design stage, the solutions developed by (Cravero, 2007) that cover both clamped and pin-loaded specimens were assessed.

\section{Estimation Procedure for the J-integral and Crack Length}

The experimental determination of $\mathrm{J}$ from the applied load and the crack-opening displacement uses a $\mathrm{J}$ estimation scheme, whose main features are recalled herafter.

$\mathrm{J}$ is split into an elastic component $\mathrm{J}_{\mathrm{el}}$ and a plastic component $\mathrm{J}_{\mathrm{pl}}$ :

$\mathrm{J}=\mathrm{J}_{\mathrm{el}}+\mathrm{J}_{\mathrm{pl}}$

The elastic component $\mathrm{J}_{\mathrm{el}}$ is computed from the mode I elastic stress intensity factor $\mathrm{K}_{\mathrm{I}}$ and the equivalent Young's modulus E':

$$
\mathrm{J}_{\mathrm{el}}=\frac{\mathrm{K}_{\mathrm{I}}^{2}}{\mathrm{E}^{\prime}}
$$


where $\mathrm{E}^{\prime}=\mathrm{E} /\left(1-v^{2}\right)$ in plane strain and $\mathrm{E}^{\prime}=\mathrm{E}$ in plane stress.

The stress intensity factor $K_{I}$ is defined as follow:

$\mathrm{K}_{\mathrm{I}}=\frac{\mathrm{P}}{\mathrm{B} \sqrt{\mathrm{W}}} \mathrm{F}(\mathrm{a} / \mathrm{W})$

where $\mathrm{F}$ is a shape factor depending on the relative crack depth $\mathrm{a} / \mathrm{W}$.

The plastic component $\mathrm{J}_{\mathrm{pl}}$ is computed by:

$$
\mathrm{J}_{\mathrm{pl}}=\eta \frac{\mathrm{A}_{\mathrm{pl}}}{\mathrm{B}_{\mathrm{N}} \mathrm{b}}
$$

where $A_{p l}$ is the plastic area under the load vs. displacement curve, $b$ is the uncracked ligament, $B_{N}$ is the net thickness. Factor $\eta$ is a non-dimensional parameter with relates the plastic contribution to the strain energy for the cracked body $A_{p l}$ with $\mathrm{J}$; it is assumed to be a function of the flawed configuration and independent of the loading level.

With the partial unloading method, the computation of $\mathrm{J}$ becomes iterative, so for the unloading step k:

$$
\begin{aligned}
& \mathrm{J}_{\mathrm{k}}=\mathrm{J}_{\mathrm{el}}^{\mathrm{k}}+\mathrm{J}_{\mathrm{pl}}^{\mathrm{k}}=\frac{\mathrm{K}_{\mathrm{I}(\mathrm{k})}^{2}\left(1-\mathrm{v}^{2}\right)}{\mathrm{E}}+\mathrm{J}_{\mathrm{pl}}^{\mathrm{k}} \\
& \left.\mathrm{J}_{\mathrm{pl}}^{\mathrm{k}}=\left\lfloor\mathrm{J}_{\mathrm{pl}}^{\mathrm{k}-1}+\frac{\eta_{\mathrm{k}}}{\mathrm{b}_{\mathrm{k}} \mathrm{B}_{\mathrm{N}}}\left(\mathrm{A}_{\mathrm{pl}}^{\mathrm{k}}-\mathrm{A}_{\mathrm{pl}}^{\mathrm{k}-1}\right)\right\rfloor 1-\frac{\gamma_{\mathrm{k}}}{\mathrm{b}_{\mathrm{k}}}\left(\mathrm{a}_{\mathrm{k}}-\mathrm{a}_{\mathrm{k}-1}\right)\right\rfloor
\end{aligned}
$$

where $a_{k}$ is the crack length at step $k, b_{k}=W-a_{k}$ is the uncracked ligament at step $k, A_{p 1}^{k}$ is the plastic area under the load vs. displacement curve at step $\mathrm{k}$.

The $\gamma$ factor is deduced from the $\eta$ factor:

$$
\gamma_{\mathrm{k}}=\left\lfloor-1+\eta_{\mathrm{k}}-\left(\left.\frac{\mathrm{b}_{\mathrm{k}}}{\eta_{\mathrm{k}}} \frac{\mathrm{d} \eta}{\mathrm{da}}\right|_{\mathrm{k}}\right)\right\rfloor
$$

During the partial unloading, the compliance $\mathrm{C}$ - inverse of the elastic stiffness of the specimen is computed: $\mathrm{C}=\Delta \mathrm{V} / \Delta \mathrm{P}$, where $\Delta \mathrm{V}$ is the COD range corresponding to the load range $\Delta \mathrm{P}$. The normalized compliance $\mu$ is obtained by:

$$
\mu=\frac{1}{1+\sqrt{\mathrm{E} \mathrm{B}_{\mathrm{ef}} \mathrm{C}}}
$$

where $B_{\text {ef }}$ is the effective thickness, equal to $B$ when there are no side grooves. Finally, the relative crack depth is computed from the normalized compliance, thanks to a relation coming from finite element results. 


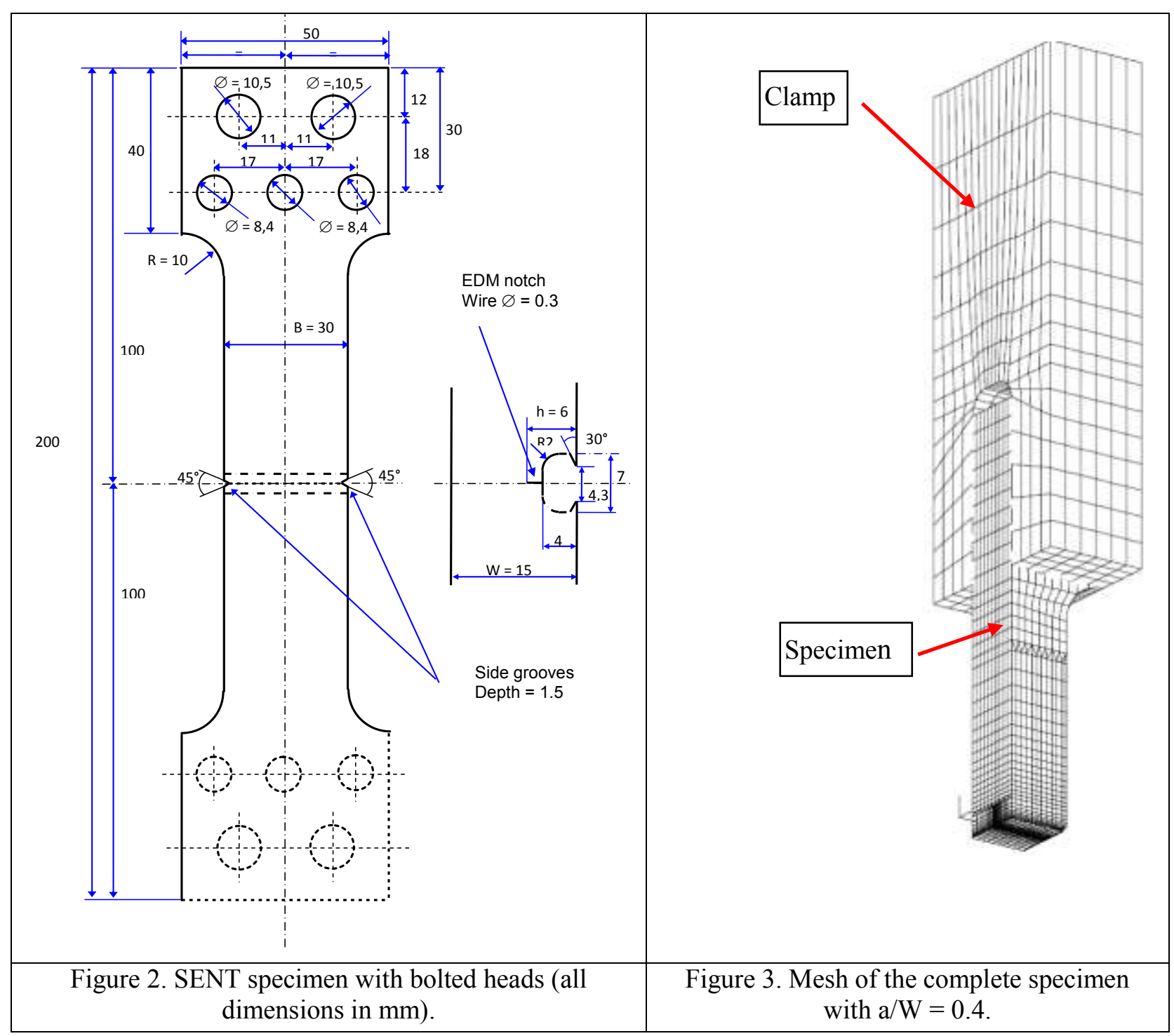

\section{Specimen Design - Finite Element Models and Computations}

In order to be able to machine specimens from schedule 8016 " pipes (outer diameter: $406 \mathrm{~mm}$ ) whose thickness is around $21 \mathrm{~mm}$, it was decided to fix the thickness $\mathrm{W}$ at $15 \mathrm{~mm}$ and the width $\mathrm{B}$ at 30 $\mathrm{mm}$ (over-square shape with $\mathrm{B} / \mathrm{W}=2$ ). In order to save material, a specimen with heads bolted to clamps was designed (Figure 2), the clamps being themselves gripped into the hydraulic grips of the servohydraulic test machine. The H/W ratio of this specimen is around 8 (where $\mathrm{H}$ represents the "day-light" between clamps). The specimen is side-grooved at $5 \%$ of $\mathrm{B}$ on each side.

A parametric finite element study was conducted to cover a large range of the relative crack depth (a/W ratio). The specimen equipped with its clamps was analyzed, using a tri-dimensional finite element model. Taking into account the symmetries, only one-quarter of the specimen was modeled, with appropriate constraints on the symmetry planes (Figure 3). The bolts are not modeled; instead, they are accounted for thanks to a solid link between elements.

All the calculations were conducted with the FE code Code_Aster (EDF in-house code). To construct the relationships between the normalized compliance $\mu$ and the relative crack length a/W, and between the shape factor $\mathrm{F}$ and the relative crack length, elastic computations were conducted with the elastic constants, $\mathrm{E}=206 \mathrm{GPa}$ and $v=0.3$. 
Evaluation of factors $\eta$ and $\gamma$ needed to compute $J$ requires nonlinear finite element analyses using an elastic-plastic constitutive model with $\mathrm{J}_{2}$ flow theory and conventional von Mises plasticity in infinitesimal strain hypothesis. A simple power-hardening stress-strain law was considered:

$$
\frac{\varepsilon}{\varepsilon_{0}}=\frac{\sigma}{\sigma_{0}} ; \quad \varepsilon \leq \varepsilon_{0} \text { and } \frac{\varepsilon}{\varepsilon_{0}}=\left(\frac{\sigma}{\sigma_{0}}\right)^{\mathrm{n}} ; \quad \varepsilon>\varepsilon_{0}
$$

where $\sigma_{0}$ and $\varepsilon_{0}$ are the reference (yield) stress and strain, and $\mathrm{n}$ is the strain-hardening exponent. Material flow properties taken by (Cravero, 2007) covering typical structural, pressure vessel and pipeline grade steels were adopted: $\mathrm{n}=5$ and $\mathrm{E} / \sigma_{0}=800$ (high hardening material), $\mathrm{n}=10$ and $\mathrm{E} / \sigma_{0}=500$ (moderate hardening material), $\mathrm{n}=20$ and $\mathrm{E} / \sigma_{0}=300$ (low hardening material).

The shape factor is given by the following formula, valid for $0.4 \leq \mathrm{a} / \mathrm{W} \leq 0.8$ :

$$
\mathrm{F}(\mathrm{a} / \mathrm{W})=0.8895-0.7969(\mathrm{a} / \mathrm{W})+8.544(\mathrm{a} / \mathrm{W})^{2}
$$

The normalized compliance is given by the following formula, valid for $0.4 \leq \mathrm{a} / \mathrm{W} \leq 0.8$ :

$$
\mathrm{a} / \mathrm{W}=1.6323-7.4965 \mu+17.19 \mu^{2}-17.399 \mu^{3}
$$

The $\eta$ factor can be computed either for the plastic component of the area under the load versus CMOD curve or from the load versus LLD curve, giving respectively $\eta_{J}^{\mathrm{CMOD}}$ and $\eta_{J}^{\mathrm{LD}}$. Moreover, as observed by Cravero, the $\eta$ value depends on the applied load (measured by $\mathrm{J}$ normalized by $b \sigma_{0}$ ) and on the stress-strain curve. As previously noticed by Cravero, the plastic $\eta$ factor reaches a "plateau » at $\mathrm{J} / \mathrm{b} \sigma_{0}=0.01 \sim 0.02$, except for the deepest cracks $(\mathrm{a} / \mathrm{W}=0.7$ and 0.8$)$, so the $\eta$ values were taken for this average level of loading. Moreover, Cravero has shown that for clamped specimens, $\eta_{\mathrm{J}}^{\mathrm{CMOD}}$ decreases steadily and almost linearly with a/W up to a/W $=0.6$. Finally, the linear fit obtained $\mathrm{for} H / \mathrm{W}=8$, valid for $0.4 \leq \mathrm{a} / \mathrm{W} \leq 0.7$, was retained:

$$
\eta_{\mathrm{J}}^{\mathrm{CMOD}}=1.26-1.1(\mathrm{a} / \mathrm{W})
$$

\section{EXPERIMENTAL WORK}

Six SENT (Figure 4) were machined in a 40-mm thick carbon-manganese plate according to the drawing Figure 2. The specimens were taken in the TS (Transverse-Short) direction of the plate, together with CT12.5 specimens. The EDM notch depth was fixed to $6 \mathrm{~mm}(\mathrm{a} / \mathrm{W}=0.4)$. The specimens were fatigue pre cracked in 4-point bending (Figure 5), to avoid damaging the backside of the notch. The inner span was reduced to $10 \mathrm{~mm}$, so that the standard 3-point bending formulae can be used (maximum load, elastic compliance and stress intensity factor). The aimed crack depth is $7.5 \mathrm{~mm}\left(\mathrm{a}_{0} / \mathrm{W}=0.5\right)$.

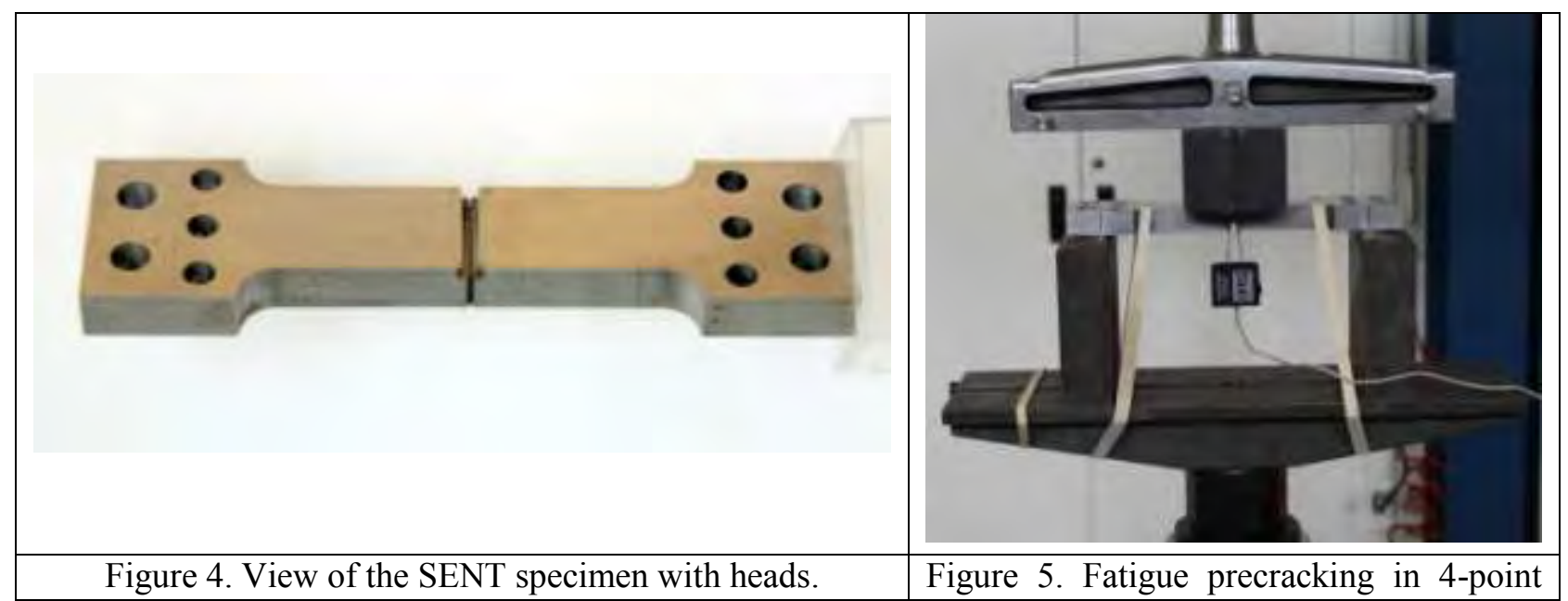


\begin{tabular}{|l|l|}
\hline & bending \\
\hline
\end{tabular}

Partial unloading tests were conducted at $20^{\circ} \mathrm{C}$ on two CT12.5 specimens and on two SENT specimens. CT12.5 test results have shown that the steel has a lower toughness in the TS direction than in the LS direction, $\mathrm{J}_{0.2}$ being close to $150 \mathrm{~kJ} / \mathrm{m}^{2}$ compared to $350 \mathrm{~kJ} / \mathrm{m}^{2}$ in the LS direction.

Figure 6 shows specimen 1695-8A ready to be tested. A clip-gage is used to measure the CMOD, two inclinometers allow to know the rotation of the clamps, and the electric drop potential method is done to follow the crack extension. Figure 7 shows the same specimen at the end of the test. One can see the large crack opening and the plastic necking of the remaining ligament.

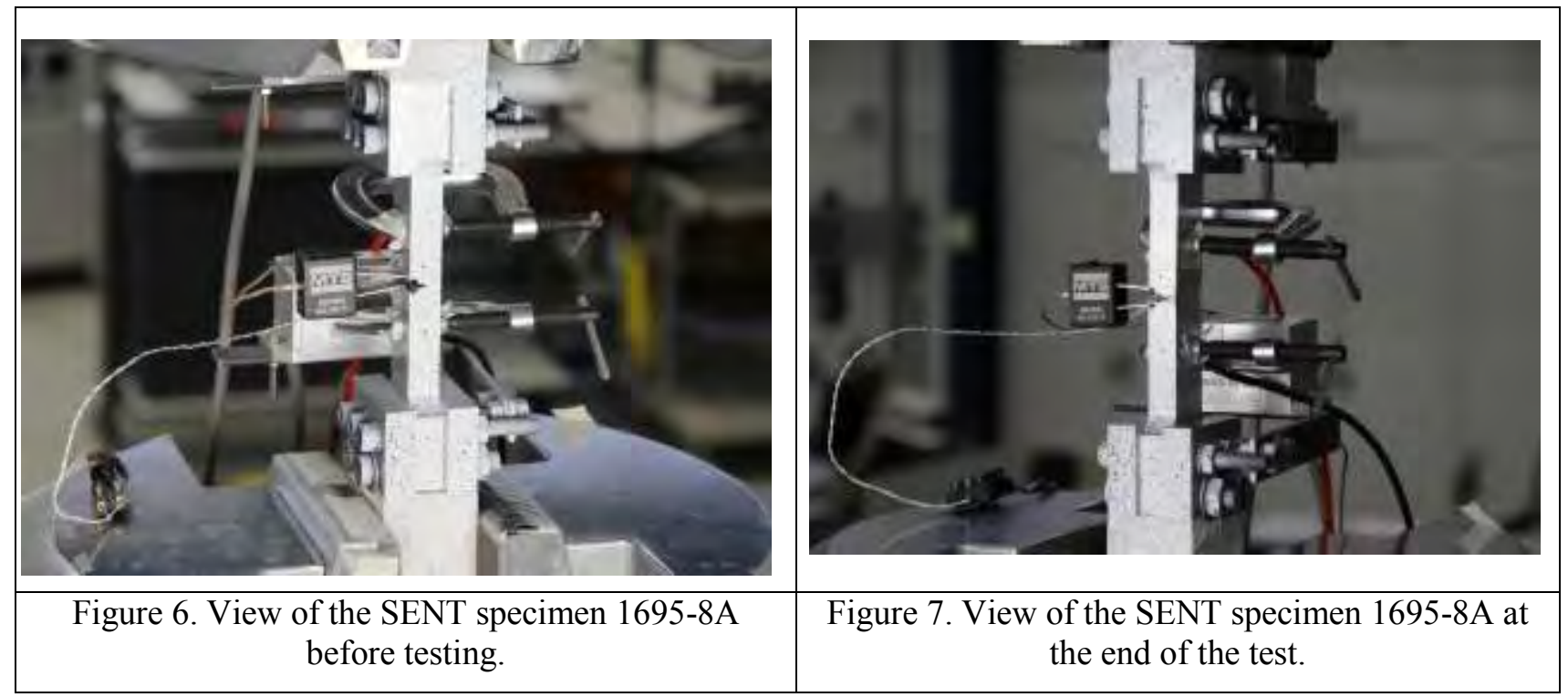

After the test, the specimens were heat tinted and broken in 3-point bending, after nitrogen cooling. Figure 8 shows the fracture surface of the specimen 1695-8B: the blue surface is the fatigue crack growth, the brown one the ductile crack growth and the light gray one the post-test brittle fracture.

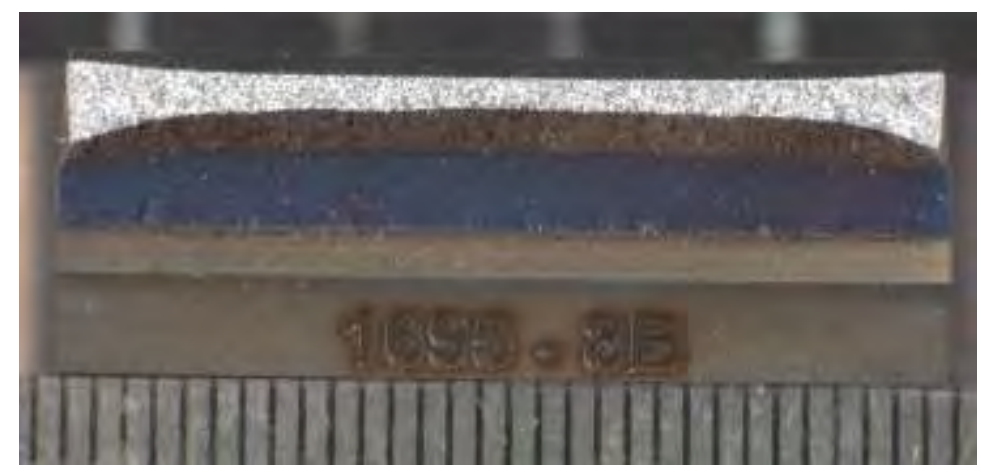

Figure 8. Fracture surface of specimen 1695-8B.

Figure 9 shows the J-R curve obtained on the CT12.5 specimens. One can observe the good agreement between the final crack extension given by optical measurement and the one given by the partial unloading method. 


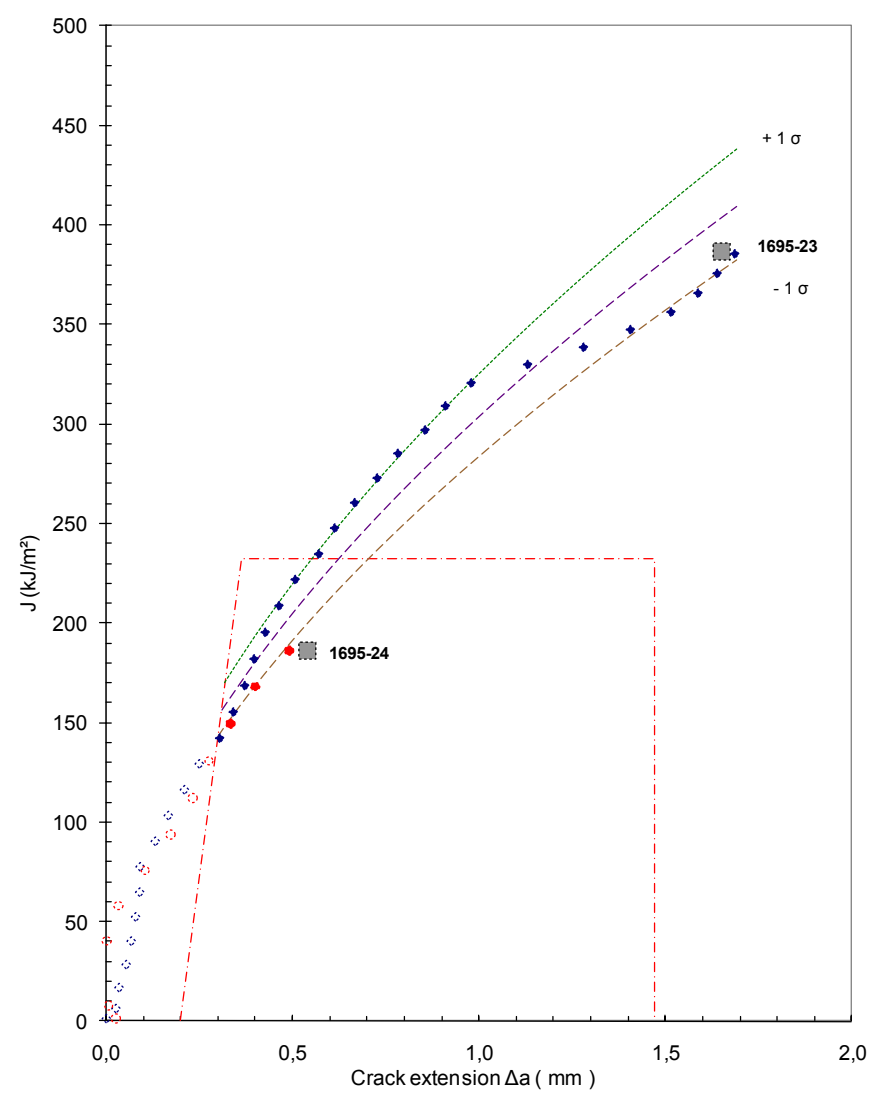

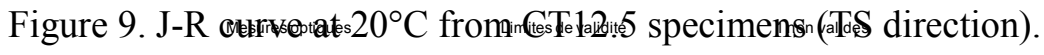

$$
1 \text { valides } 2 \text { non valides } 2 \text { valides }
$$

Four fracture toughness tests were conducted on the CT12.5 specimens, one at $-60^{\circ} \mathrm{C}$ and three at $-100^{\circ} \mathrm{C}$. At $-60^{\circ} \mathrm{C}$, the specimen remained ductile so it was decided to test the other specimens at $-100^{\circ} \mathrm{C}$ to obtain a valid $\mathrm{K}_{\mathrm{IC}}$ value. At $-100^{\circ} \mathrm{C}$, the $\mathrm{K}_{\mathrm{IC}}$ value is around $30 \mathrm{MPa} \sqrt{\mathrm{m}}$ whereas the $\mathrm{K}_{\mathrm{IC}}$ values range from 51 to $91 \mathrm{MPa} \sqrt{\mathrm{m}}$ Fimure 10 chowe the I nad_CMON curvec shtained on the four cnerimens.

Prestation M6652 : Courbe Force-Ouverture

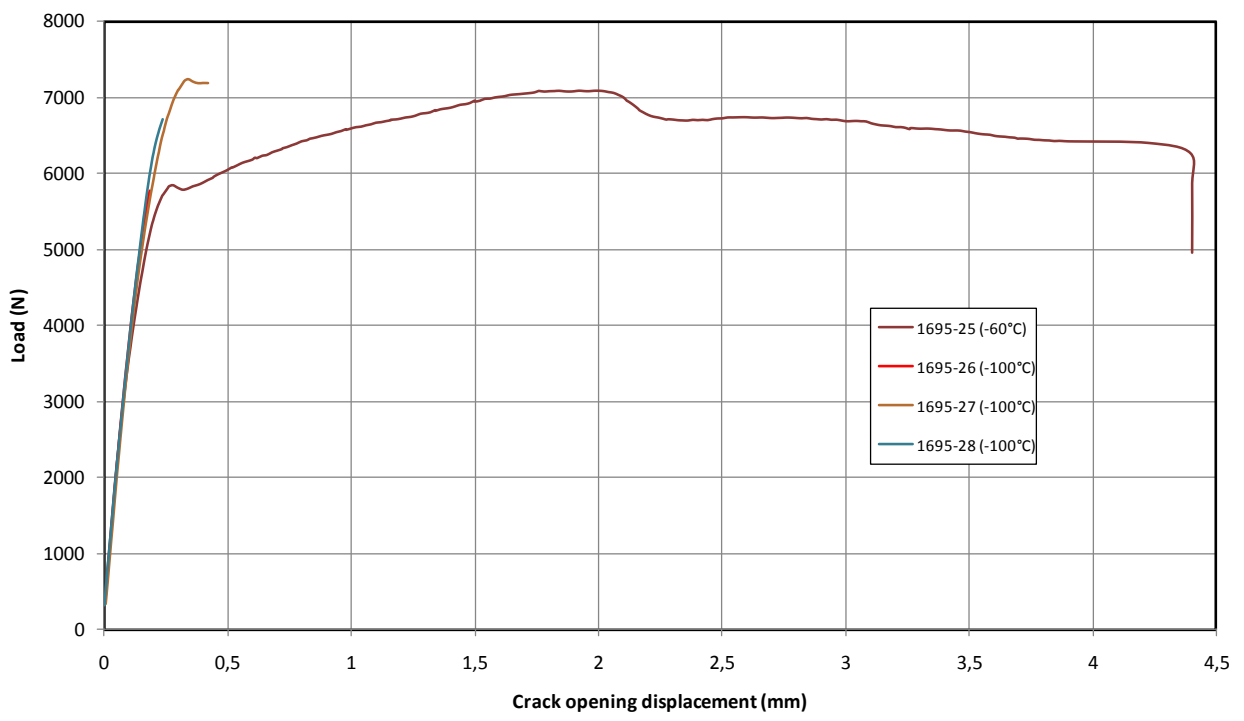

Figure 10. Load versus CMOD curves for the CT12.5 specimens tested at $-60^{\circ} \mathrm{C}$ and $-100^{\circ} \mathrm{C}$. 
In order to analyze the tests by FEM, tensile tests were conducted at several temperatures between $20^{\circ} \mathrm{C}$ and $-100^{\circ} \mathrm{C}$, at a strain rate of $10^{-3} / \mathrm{s}$. Figure 11 shows the true stress - true strain curves obtained. One can see the strong increase of the tensile properties between $-50^{\circ} \mathrm{C}$ and $-100^{\circ} \mathrm{C}$. The length of the Lüders plateau seems to increase whøaldha temperatamedereasens long

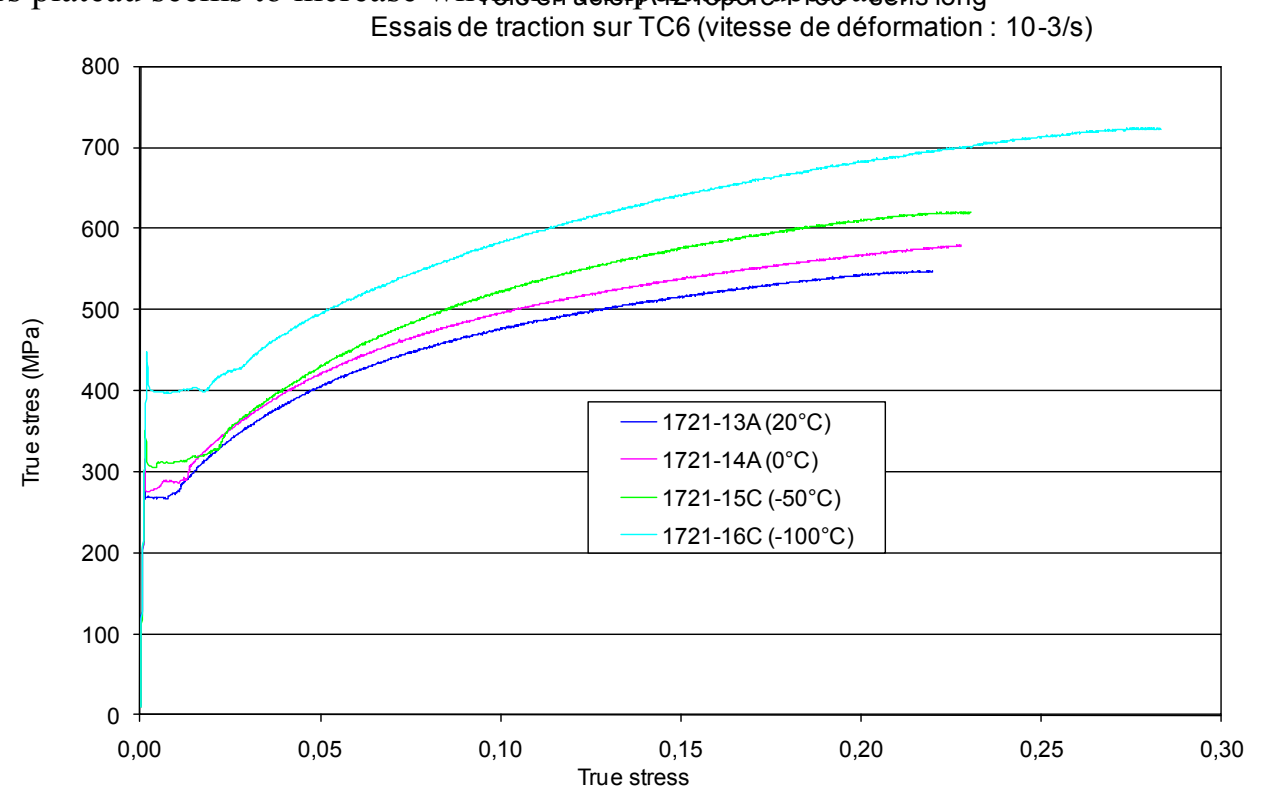

Figure 11. Stress-strain curves of the carbon-manganese steel between $20^{\circ} \mathrm{C}$ and $-100^{\circ} \mathrm{C}$.

\section{CONCLUSION}

A clamped SENT specimen with heads was designed, and the factors $F, \mu$ and $\eta$ needed to compute $\mathrm{J}$ from the experimental load versus CMOD curve were developed, to be used with the unloading compliance technique. A good agreement was obtained with the solutions obtained previously by (Cravero, 2007). The preliminary tests conducted at $20^{\circ} \mathrm{C}$ on four specimens have shown that despite several experimental problems, the procedure gives promising results.

New specimens have been machined with shallower notches $(\mathrm{a} / \mathrm{W}=0.4)$, to get $\mathrm{a}_{0} / \mathrm{W}=0.5$ after fatigue pre cracking. Fatigue pre cracking was conducted in 4-point bending to avoid damaging the back of the notch. Moreover, the specimens were cut in the TS (Transverse-Short) direction of the plate to get lower toughness properties, and less plasticity during the tests. New tests have been conducted, first at $20^{\circ} \mathrm{C}$ to check that the procedure is well established in the ductile regime, and then around $-60^{\circ} \mathrm{C}$ in the brittle to ductile region, to put in evidence the geometry effects between CT specimens and SENT specimens.

One should mention that various proposals are presently available (DNV, 2006; recommended practice from Exxon Mobile; Shen, 2008) to try to standardize SENT specimen size and test procedures:

- $\quad$ over-square shape $(B=2 W)$ versus square shape $(B=W)$,

- value of the $\mathrm{H} / \mathrm{W}$ ratio (ten being the most common value),

- introduction of side-grooves,

- necessity to fatigue precrack the specimen,

- formulae needed to calculate $\mathrm{J}$ and the compliance. 


\section{NOMENCLATURE}

$\begin{array}{ll}\text { a } & \text { Crack depth } \\ \mathrm{B} & \text { Specimen thickness } \\ \mathrm{B}_{\mathrm{N}} & \text { Net thickness of a side-grooved specimen } \\ \mathrm{b} & \text { Remaining ligament } \\ \mathrm{CT} & \text { Compact tension specimen } \\ \mathrm{E} & \text { Young's Modulus } \\ \mathrm{H} & \text { Net length of a SENT specimen (“Day-light” between grips) } \\ \mathrm{J} & \text { J-integral } \\ \mathrm{J}_{\mathrm{el}} & \text { Elastic component of J-integral } \\ \mathrm{J}_{\mathrm{pl}} & \text { Plastic component of J-integral } \\ \mathrm{P} & \text { Applied load } \\ \mathrm{SENT} & \text { Single-edge notch tension specimen } \\ \mathrm{W} & \text { Specimen width } \\ \Delta \mathrm{a} & \text { Crack extension } \\ \gamma & \text { Non-dimensional factor to account for crack growth effects on J-integral } \\ \eta & \text { Non-dimensional factor, relating the plastic work with the J-integral } \\ \mu & \text { Non-dimensional compliance } \\ \nu & \text { Poisson's ratio }\end{array}$

\section{REFERENCES}

Cravero, S., and Ruggieri, C. (2007). "Estimation procedure of J-resistance curves for SE(T) fracture specimens using unloading compliance", Engineering Fracture Mechanics, 74, pp. 2735-2757

DNV (2006). "Fracture control for pipeline installation methods introducing cyclic plastic strain", Recommended practice DNV-RP-F108, Det Norske Veritas

Le Delliou, P., and El-Gharib, J. (2012). "Development of test on SENT specimens to study geometry effects", Proceedings of ASME 2012 PV\&P Conference, paper PVP\#2012-78110

Nyhus, B., Loria Polenco, M., and Ørjasaether, O. (2003). "SENT specimens an alternative to SENB specimens for fracture mechanics testing of pipelines", Proceedings of OMAE3, paper OMAE200337370

Park, D.Y., Tyson, W.R., Gianetto, J.A., Shen, G. and Eagleson, R.S. (2010). "Evaluation of fracture toughness of X100 pipe steel using (SE)B and clamped SE(T) single specimens", Proceedings of $8^{\text {th }}$ IPC Conference, paper IPC2010-31282

Shen, G., Bouchard, R., Gianetto, J.A., and Tyson, W.R. (2008). "Fracture toughness evaluation of high strength steel pipe", Proceedings of ASME 2008 PV\&P Conference, paper PVP\#2008-61100

Xu, J., Zhang, Z.L., Østby, E., Nyhus, B., and Sun, D.B. (2009). "Effects of crack depth and specimen size on ductile crack growth of SENT and SENB specimens for fracture mechanics evaluation of pipeline steels", International Journal of Pressure Vessels and Piping, 86, pp. 787-797

Zhou, D.W. (2011). "Measurement and modelling of R-curves for low constraint specimens", Engineering Fracture Mechanics, 78, pp. 605-622 